IOSR Journal of Pharmacy

ISSN: 2250-3013, www.iosrphr.org

||| Volume 2 Issue 5 ||| Sep-Oct. 2012 || || PP.56-60

\title{
Statins modulate the murine immune response and enhance graft longevity in human kidney transplant recipients
}

\author{
Elias A. Rahal ${ }^{1 *}$, Marita Chakhtoura ${ }^{1}$, Christelle P. El-Haibi ${ }^{1}$, Rana Abu \\ Dargham $^{2}$, Raja B. Khauli ${ }^{2}$, Walid Medawar ${ }^{3}$, Alexander M. Abdelnoor ${ }^{1 *}$ \\ ${ }^{I}$ Department of Experimental Pathology, Immunology and Microbiology, Faculty of Medicine, \\ American University of Beirut, Beirut, Lebanon \\ ${ }^{2}$ Department of Surgery, American University of Beirut Medical Center, Beirut, Lebanon \\ ${ }^{3}$ Department of Internal Medicine, American University of Beirut Medical Center, Beirut, Lebanon
}

\begin{abstract}
Multiple immunomodulatory effects have been described for statins. We sought to assess their effects on components of the immune response in mice in addition to examining their effects in human transplant recipients. Multiple groups of BALB/c mice were challenged with egg albumin and treated with various regimen of atorvastatin. Serum and spleen samples were then collected. Mice sera were analyzed for anti-egg albumin levels by enzyme linked immunosorbent assay (ELISA) while splenocytes were assessed for $I L-4$ and IFN-y expression by reverse transcriptase polymerase chain reaction (RT-PCR). Atorvastatin treatment markedly decreased anti-egg albumin antibody, IL-4 and IFN- $\gamma$ production particularly in a group of mice receiving atorvastatin for 5 days post-challenge. To examine the effect of statins on graft longevity in kidney allograft recipients, 111 patients were monitored for graft rejection or loss within a period of 3 years post-transplantation. Fifteen of 90 (16.66\%) of patients who were not on a statin had a rejection episode or lost the graft while 1 of 21 (4.76\%) patients on a statin had a rejection episode. Therefore, statins appear to have suppressive effects on various components of the immune response. They also seem to decrease the risk of graft rejection or loss in transplant recipients.
\end{abstract}

\section{INTRODUCTION}

Statins are ubiquitously prescribed agents used for the treatment of hyperlipidemia, in particular for decreasing blood cholesterol levels. They are 3-hydroxy-3-methylglutaryl-coenzyme A (HMG-CoA) reductase inhibitors that inhibit mevalonate biosynthesis, the rate-limiting step of cholesterol production $[1,2]$. They comprise a group of compounds that are natural or semisynthetic derivatives of fungal metabolites in addition to those that are purely synthetic [3]. A decrease in the synthesis of cholesterol results in upregulated expression of hepatic LDL (low-density lipoprotein) receptors and consequential enhanced clearance of bloodstream LDL [4].

The role of statin therapy in reducing the risk of cardiovascular disease is generally well established [57]. This was initially attributed to the reduction of plasma cholesterol level; however, multiple studies have since shown that statins have several beneficial effects that extend beyond altering cholesterol metabolism. These pleiotropic effects of statins involve improvement of endothelial function, prevention of thrombosis, enhanced stability of atherosclerotic plaques, anti-oxidation, immunomodulation and abatement of the inflammatory reaction [8]. Some of the mechanisms behind these effects are directly related to inhibition of mevalonate synthesis and the resulting reduced production of non-sterol isoprenoid intermediates whereas other mechanisms are believed to be independent of the inhibition of cholesterol biosynthesis [9]. As a consequence of these pleiotropic effects, statins may be useful in a wide range of diseases other than hypercholesterolemia and heart-associated conditions. These include immune-mediated disorders such as rheumatoid arthritis [10] and multiple sclerosis [11]. They also have potential therapeutic applications in osteoporosis [12], cancer [13-15], cerebrovascular disorders [16], Alzheimer's disease and Parkinson's disease [11] among others. Further research and clinical trials are required to substantiate the use of statins in these conditions. In addition to the conditions mentioned above statins may also benefit transplant recipients [17, 18] owing to the immune mechanisms generally behind a rejection reaction or the loss of a grafted organ. We sought to assess the effect of statins on components of the immune response in mice in addition to examining the effects of these drugs on transplant recipients. 


\section{Mouse groups and treatments}

\section{MATERIALS AND METHODS}

Four groups of animals each containing 9 female 8-week old female BALB/c mice were challenged with egg albumin $(0.2 \mathrm{mg})$ via intraperitoneal injection. Mice received atorvastatin (Lipitor ${ }^{\circledR}$, Pfizer Inc., NY, USA) at a dose of $40 \mathrm{mg} / \mathrm{Kg} /$ mouse either directly after challenge, 24 hours before or 24 hours after challenge. One group received a daily atorvastatin dose up to 5 days after challenge. Two additional mouse groups served as control: one was challenged with egg albumin but was not treated with atorvastatin while the other received the sterile phosphate buffered saline (PBS) used to prepare all injections. Injection volumes did not exceed 0.5 $\mathrm{ml}$ per mouse per day. Three mice per group were euthanized on days 6 and 12 post immunization with egg albumin. Serum samples were collected and pooled upon cardiac puncture and spleen samples were also obtained from the euthanized animals. Approval for work utilizing mice was obtained from the Institutional Animal Care and Use Committee (IACUC) at the American University of Beirut.

\section{Enzyme-linked immunosorbent assay (ELISA) for anti-egg albumin levels}

Serum levels of anti-egg albumin were determined using ELISA. A 96 well polystyrene plate was coated with egg albumin by addition of $50 \mu \mathrm{l}$ of a solution of egg albumin in PBS $(25 \mu \mathrm{g} / \mathrm{ml})$ into each well. This was followed by incubation at $4^{\circ} \mathrm{C}$ overnight. The plate was then washed 3 times with $300 \mu 1$ of PBS per well using an automated washer (Bio-Tek® Instruments,VT). Subsequently $25 \mu 1$ of test sera were added per well. Wells that did not include mouse sera were included as negative controls and used as blanks for antibody concentration calculation. This was followed by incubation at $37^{\circ} \mathrm{C}$ for $30 \mathrm{~min}$; upon incubation the wells were washed as described above. Subsequently, $25 \mu \mathrm{l}$ of a peroxidase-conjugated mouse anti-IgG in PBS $(1 \mu \mathrm{g} / \mathrm{ml})$ were added per well. This was followed by incubation at $37^{\circ} \mathrm{C}$ for $30 \mathrm{~min}$; the plate was then washed as described above. Following this step $25 \mu \mathrm{l}$ of $3,3^{\prime}, 5,5^{\prime}$ tetramethylbenzidine (TMB) were added per well and incubated for $30 \mathrm{~min}$ in the dark. Reactions were stopped with $25 \mu \mathrm{l}$ of $3 \mathrm{M} \mathrm{NaOH}$ per well. Absorbances were then read with a plate reader (Bio-Tek Instruments) at $450 \mathrm{~nm}$.

\section{Reverse transcriptase polymerase chain reaction (RT-PCR) for IL-4 and IFN- $\gamma$}

RNA was isolated from mouse splenocytes using the TRIR ${ }^{\circledR}$ reagent (ABgene, UK) according to the manufacturer's instructions. cDNA synthesis was then carried out on the RNA samples using the Ready-toGo $^{\mathrm{TM}}$ You-Prime-First-Strand Beads (Amersham Pharmacia Biotech, Piscataway, NJ) following the manufacturer's recommendations and using $100 \mathrm{ng}$ of RNA per cDNA synthesis reaction. PCR was then carried out in $100 \mu \mathrm{l}$ reactions containing $33 \mu \mathrm{l}$ of the synthesized cDNA, 40 pmol of the forward primer, $40 \mathrm{pmol}$ of the reverse primer and 2.5 units of Taq DNA polymerase. Previously published primers [19] were used for IL-4 transcript detection. These had the sequences: 5'-TCGCCATTTTGAACGAGGTC-3' and 5'-GAA AAG CCC GAA AGA GTC TC- $3^{\prime}$. Previously published primers [19] were used for IFN- $\gamma$ transcript detection. These had the sequences: 5'-AAAGAG ATA ATCTGGCTCTGC-3' and 5'-GCTCTGAGACAATGAACGCT-3'. PCR consisted of 35 cycles of $93^{\circ} \mathrm{C}$ for $2 \mathrm{~min}, 60^{\circ} \mathrm{C}$ for $1 \mathrm{~min}$ and $71^{\circ} \mathrm{C}$ for $2 \mathrm{~min}$.

\section{Kidney allograft recipients}

One hundred and eleven kidney transplant recipients were studied. Of these, 32 were females and 79 were males. The mean age of the study population was 44.37 (Std. deviation: 15.33). Rejection or loss of the graft within a maximum period of 3 years following transplantation was monitored. Twenty one patients were on statins including 10 who were on simvastatin, 5 on atorvastatin, 4 on fluvastatin, 1 on pravastatin and 1 on rosuvastatin. Approval of the Institutional Review Board (IRB) at the American University of Beirut was obtained for the performed studies.

\section{RESULTS}

\section{Effects of atorvastatin on the immune response in mice}

To assess the effect of statins on the immune system, we examined responses in mice challenged with egg albumin and treated with atorvastatin as described in the Materials and Methods section. We observed a two-fold reduction in anti-egg albumin antibody levels in the group that received daily atorvastatin doses for 5 days when mouse sera were analyzed 6 days after challenge. This same group showed a four-fold reduction in antibody levels 12 days after challenge (Figure 1). Other treatments did not result in marked antibody level changes. Analysis of IL-4 and IFN- $\gamma$ expression on RNA from splenocytes isolated from the mouse groups treated as explained above was then performed using RT-PCR. A sharp decline in detection of IL-4 expression was seen in the mouse group that received a daily dose of atorvastatin for 5 days when splenocytes were tested 6 days after egg albumin challenge. Expression of IL-4 was not detectable 12 days post-challenge in this group. On the other hand, IFN- $\gamma$ expression was undetectable in this group on both days 6 and 12 post-challenge. Expression of these cytokines was detectable by RT-PCR in splenocytes from the other mouse groups [20]. 


\section{Effect of statins on graft longevity}

Fifteen of $90(16.66 \%)$ kidney allograft recipients who were not on a statin had a rejection episode or lost the graft. On the other hand, only 1 of $21(4.76 \%)$ receipients on a statin had a rejection episode. This patient was on fluvastatin.

\section{DISCUSSION}

We intended to assess the effects of statins on the immune system in mice and on the graft longevity in kidney allograft recipients. These agents have lipid-lowering effects and are prescribed to transplant patients on immunosuppressive drugs that increase serum cholesterol levels. We observed suppression in antibody production upon antigenic challenge in mice in addition to suppression of IL-4 and IFN- $\gamma$ expression. This supports previous observations by our group and others indicating that statins can simultaneously curb Th1 and Th2 immune responses [20-22]. Moreover, we have observed an up to four-fold decrease in the survival rate of Candida albzicans or Escherichia coli-infected mice treated with atorvastatin. This was in comparison to infected mice that were not treated with this statin (manuscript in preparation). This indicates that the immunosuppressive effects of statins may curb immune responses required for combating infections.

On the other hand, we observed an approximate three-fold decrease in the risk of graft rejection in kidney graft recipients who were treated with a statin. We have previously ruled out other factors that may potentially affect graft longevity including whether the graft was obtained from a living related donor or an unrelated one; the degree of HLA-disparity also seemed to have no effect on graft longevity in our previous studies [23, 24]. Although we have previously shown that triple immunosuppressive therapy (with cyclosporine, mycophenolate mofetil and prednisone) seems to have a less protective effect on graft longevity compared to quadruple therapy (additionally includes sirolimus), the immunosuppressive regimen implemented appears to have no bearing on the effect of statins as we previously demonstrated [25]. Therefore, this protective effect of statins is seemingly independent of the immunosuppressive regimen administered.

Multiple mechanisms may contribute to the effects of statins we describe herein. These agents have been shown to inhibit signaling mediated by mitogen-activated protein kinase (MAPK) and peroxisome proliferator activated receptors (PPAR) [26] in addition to nuclear factor kappa B (NFkB) [27]. These pathways play a role in mediating inflammation. Statins also reduce the production of various cytokines [27-30] in addition to that of C-reactive protein (CRP) [31]. Moreover they seem to modulate the proliferation and activation of various types of cells with roles in immune pathways [32-36]. Additionally they decrease the expression of adhesion molecules [37, 38] and human leukocyte antigens (HLA) of class II type [39].

\section{CONCLUSIONS}

Statins appear to have clinical benefits in kidney transplant recipients. On one hand, they decrease cholesterol levels typically induced by the other immunosuppressive drugs administered; on the other, they considerably decrease the risk of graft rejection or loss. Further clinical studies should be performed to assess the utility of statins in various types of organ transplant recipients. Moreover, the optimum types of statins and their dosage regimen should be examined.

\section{ACKNOWLEDGEMENTS}

The authors wish to thank the Lebanese National Council for Scientific Research (CNRS) for partially funding this work.

\section{REFERENCES}

[1]. Endo, A, Kuroda M,Tanzawa K. Competitive inhibition of 3-hydroxy-3-methylglutaryl coenzyme A reductase by ML-236A and ML-236B fungal metabolites, having hypocholesterolemic activity. FEBS Lett. 1976;72: 323-326.

[2]. Istvan, ES,Deisenhofer J. Structural mechanism for statin inhibition of HMG-CoA reductase. Science. 2001;292: 1160-1164.

[3]. Barrios-Gonzalez, J,Miranda RU. Biotechnological production and applications of statins. Appl Microbiol Biotechnol. 2010;85: 869-883.

[4]. Ma, PT, Gil G, Sudhof TC, Bilheimer DW, Goldstein JL,Brown MS. Mevinolin, an inhibitor of cholesterol synthesis, induces mRNA for low density lipoprotein receptor in livers of hamsters and rabbits. Proc Natl Acad Sci U S A. 1986;83: 8370-8374.

[5]. Delahoy, PJ, Magliano DJ, Webb K, Grobler M,Liew D. The relationship between reduction in low-density lipoprotein cholesterol by statins and reduction in risk of cardiovascular outcomes: an updated meta-analysis. Clin Ther. 2009;31: 236-244.

[6]. Mills, EJ, Rachlis B, Wu P, Devereaux PJ, Arora P,Perri D. Primary prevention of cardiovascular mortality and events with statin treatments: a network meta-analysis involving more than 65,000 patients. J Am Coll Cardiol. 2008;52: 1769-1781.

[7]. Thavendiranathan, P, Bagai A, Brookhart MA,Choudhry NK. Primary prevention of cardiovascular diseases with statin therapy: a meta-analysis of randomized controlled trials. Arch Intern Med. 2006;166: 2307-2313. 
[8]. Athyros, VG, Kakafika AI, Tziomalos K, Karagiannis A,Mikhailidis DP. Pleiotropic effects of statins--clinical evidence. Curr Pharm Des. 2009;15: 479-489.

[9]. Blum, A,Shamburek R. The pleiotropic effects of statins on endothelial function, vascular inflammation, immunomodulation and thrombogenesis. Atherosclerosis. 2009;203: 325-330.

[10]. Costenbader, KH,Coblyn JS. Statin therapy in rheumatoid arthritis. South Med J. 2005;98: 534-540; quiz 541, 572.

[11]. Wood, WG, Eckert GP, Igbavboa U,Muller WE. Statins and neuroprotection: a prescription to move the field forward. Ann N Y Acad Sci. 2010;1199: 69-76.

[12]. Pasco, JA, Kotowicz MA, Henry MJ, Sanders KM,Nicholson GC. Statin use, bone mineral density, and fracture risk: Geelong Osteoporosis Study. Arch Intern Med. 2002;162: 537-540.

[13]. Campbell, MJ, Esserman LJ, Zhou Y, Shoemaker M, Lobo M, Borman E, Baehner F, Kumar AS, Adduci K, Marx C, Petricoin EF, Liotta LA, Winters M, Benz S,Benz CC. Breast cancer growth prevention by statins. Cancer Res. 2006;66: 8707-8714.

[14]. Demierre, MF, Higgins PD, Gruber SB, Hawk E,Lippman SM. Statins and cancer prevention. Nat Rev Cancer. 2005;5: 930-942.

[15]. Hamilton, RJ,Freedland SJ. Review of recent evidence in support of a role for statins in the prevention of prostate cancer. Curr Opin Urol. 2008;18: 333-339.

[16]. Di Napoli, M. Benefits of statins in cerebrovascular disease. Curr Opin Investig Drugs. 2004;5: 295-305.

[17]. Wiesbauer, F, Heinze G, Mitterbauer C, Harnoncourt F, Horl WH,Oberbauer R. Statin use is associated with prolonged survival of renal transplant recipients. J Am Soc Nephrol. 2008;19: 2211-2218.

[18]. Wu, AH, Ballantyne CM, Short BC, Torre-Amione G, Young JB, Ventura HO, Eisen HJ, Radovancevic B, Rayburn BK, Lake KD, Yancy CW, Jr., Taylor DO, Mehra MR, Kubo SH, Fishbein DP, Zhao XQ,O'Brien KD. Statin use and risks of death or fatal rejection in the Heart Transplant Lipid Registry. Am J Cardiol. 2005;95: 367372.

[19]. Favre, N, Bordmann G,Rudin W. Comparison of cytokine measurements using ELISA, ELISPOT and semiquantitative RT-PCR. J Immunol Methods. 1997;204: 57-66.

[20]. El-Haibi, C, Rahal E, Khauli RB,Abdelnoor AM. Effect of atorvastatin on antibody, interleukin-4 and gammainterferon production in mice immunized with egg albumin. Immunopharmacol Immunotoxicol. 2006;28: 459-470.

[21]. McKay, A, Leung BP, McInnes IB, Thomson NC,Liew FY. A novel anti-inflammatory role of simvastatin in a murine model of allergic asthma. J Immunol. 2004;172: 2903-2908.

[22]. Leung, BP, Sattar N, Crilly A, Prach M, McCarey DW, Payne H, Madhok R, Campbell C, Gracie JA, Liew FY,McInnes IB. A novel anti-inflammatory role for simvastatin in inflammatory arthritis. J Immunol. 2003;170: 1524-1530.

[23]. Rahal, EA, Chakhtoura M, Abu Dargham R, Khauli RB, Medawar W,Abdelnoor AM. Advantages of sirolimus in a calcineurin-inhibitor minimization protocol for the immunosuppressive management of kidney allograft recipients. ISRN Immunology. 2011;

[24]. Abdelnoor, AM, Ajib R, Chakhtoura M, Daouk M, Medawar W, Uwaydah M, Sawah SI,Khauli RB. Influence of HLA disparity, immunosuppressive regimen used, and type of kidney allograft on production of anti-HLA class-I antibodies after transplant and occurrence of rejection. Immunopharmacol Immunotoxicol. 2009;31: 83-87.

[25]. Rahal, EA, Chakhtoura M, Dargham RA, Khauli RB, Medawar W,Abdelnoor AM. The impact of prophylactic antiviral agents and statin administration on graft longevity in kidney allograft recipients. Immunopharmacol Immunotoxicol. 2012; doi: 10.3109/08923973.2011.653648

[26]. Kleemann, R, Verschuren L, de Rooij BJ, Lindeman J, de Maat MM, Szalai AJ, Princen HM,Kooistra T. Evidence for anti-inflammatory activity of statins and PPARalpha activators in human C-reactive protein transgenic mice in vivo and in cultured human hepatocytes in vitro. Blood. 2004;103: 4188-4194.

[27]. Wang, HR, Li JJ, Huang CX,Jiang H. Fluvastatin inhibits the expression of tumor necrosis factor-alpha and activation of nuclear factor-kappaB in human endothelial cells stimulated by C-reactive protein. Clin Chim Acta. 2005;353: 53-60.

[28]. Rosenson, RS, Tangney CC,Casey LC. Inhibition of proinflammatory cytokine production by pravastatin. Lancet. 1999;353: 983-984.

[29]. Romano, M, Diomede L, Sironi M, Massimiliano L, Sottocorno M, Polentarutti N, Guglielmotti A, Albani D, Bruno A, Fruscella P, Salmona M, Vecchi A, Pinza M,Mantovani A. Inhibition of monocyte chemotactic protein-1 synthesis by statins. Lab Invest. 2000;80: 1095-1100.

[30]. Kothe, H, Dalhoff K, Rupp J, Muller A, Kreuzer J, Maass M,Katus HA. Hydroxymethylglutaryl coenzyme A reductase inhibitors modify the inflammatory response of human macrophages and endothelial cells infected with Chlamydia pneumoniae. Circulation. 2000;101: 1760-1763.

[31]. Asher, J,Houston M. Statins and C-reactive protein levels. J Clin Hypertens (Greenwich). 2007;9: 622-628.

[32]. Weber, C, Erl W,Weber PC. Lovastatin induces differentiation of Mono Mac 6 cells. Cell Biochem Funct. 1995;13: 273-277.

[33]. Chakrabarti, R,Engleman EG. Interrelationships between mevalonate metabolism and the mitogenic signaling pathway in T lymphocyte proliferation. J Biol Chem. 1991;266: 12216-12222.

[34]. Cutts, JL,Bankhurst AD. Reversal of lovastatin-mediated inhibition of natural killer cell cytotoxicity by interleukin 2. J Cell Physiol. 1990;145: 244-252.

[35]. Rudich, SM, Mongini PK, Perez RV,Katznelson S. HMG-CoA reductase inhibitors pravastatin and simvastatin inhibit human B-lymphocyte activation. Transplant Proc. 1998;30: 992-995. 
[36]. Katznelson, S, Wang XM, Chia D, Ozawa M, Zhong HP, Hirata M, Terasaki PI,Kobashigawa JA. The inhibitory effects of pravastatin on natural killer cell activity in vivo and on cytotoxic T lymphocyte activity in vitro. J Heart Lung Transplant. 1998;17: 335-340.

[37]. Liu, L, Moesner P, Kovach NL, Bailey R, Hamilton AD, Sebti SM,Harlan JM. Integrin-dependent leukocyte adhesion involves geranylgeranylated protein(s). J Biol Chem. 1999;274: 33334-33340.

[38]. Weber, C, Erl W, Weber KS,Weber PC. HMG-CoA reductase inhibitors decrease CD11b expression and CD11bdependent adhesion of monocytes to endothelium and reduce increased adhesiveness of monocytes isolated from patients with hypercholesterolemia. J Am Coll Cardiol. 1997;30: 1212-1217.

[39]. Kwak, B, Mulhaupt F, Myit S,Mach F. Statins as a newly recognized type of immunomodulator. Nat Med. 2000;6: 1399-1402.

\section{Figure legends}

Figure 1. Anti-egg albumin antibody levels in mice challenged with egg albumin and treated with atorvastatin. Six groups of mice were treated as indicated in the text and respective sera were analyzed by ELISA. The group that did not receive egg albumin or atorvastatin was administered sterile PBS instead. Antibody levels are normalized to those detected in the mouse group challenged with egg albumin but not treated with atorvastatin

Figure 1

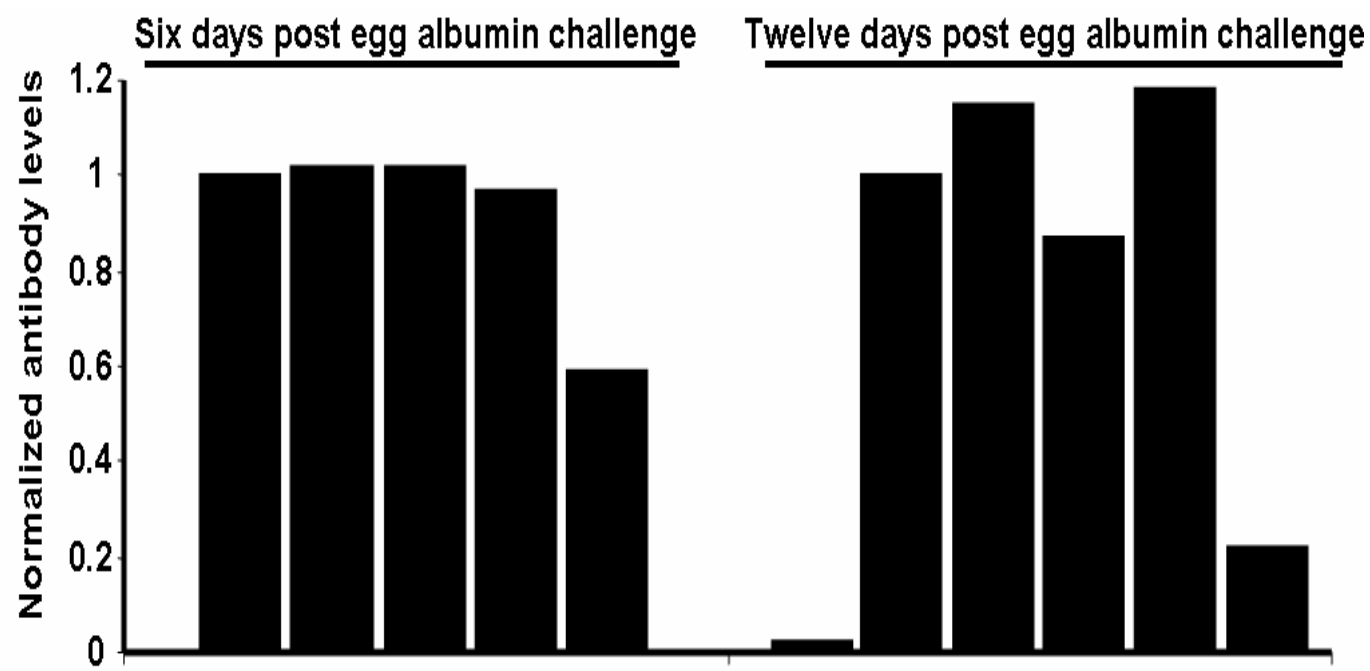

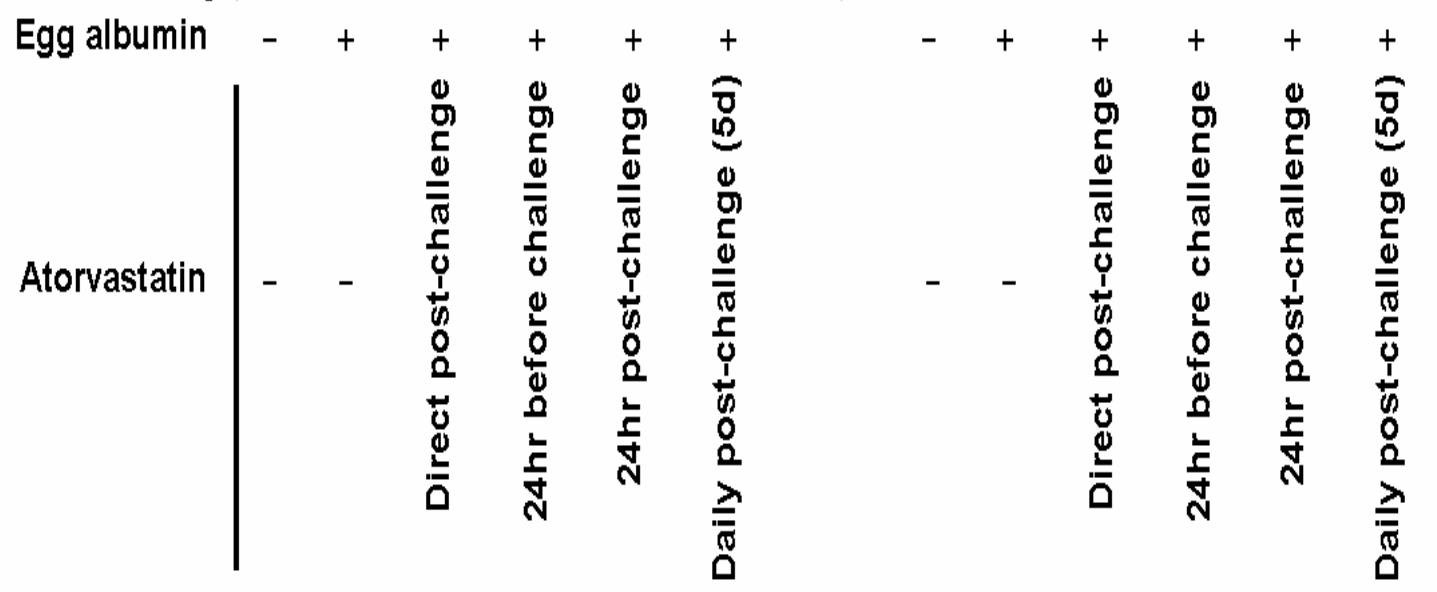

